\title{
Exercise training reduces fatty acid availability and improves the insulin sensitivity of glucose metabolism
}

\author{
F. Shojaee-Moradie • K. C. R. Baynes $\cdot$ C. Pentecost • \\ J. D. Bell • E. L. Thomas • N. C. Jackson • \\ M. Stolinski • M. Whyte • D. Lovell • S. B. Bowes • \\ J. Gibney • R. H. Jones • A. M. Umpleby
}

Received: 25 July 2006 / Accepted: 6 September 2006 / Published online: 6 December 2006

(C) Springer-Verlag 2006

\begin{abstract}
Aims/hypothesis It is not known whether the beneficial effects of exercise training on insulin sensitivity are due to changes in hepatic and peripheral insulin sensitivity or whether the changes in insulin sensitivity can be explained by adaptive changes in fatty acid metabolism, changes in visceral fat or changes in liver and muscle triacylglycerol content. We investigated the effects of 6 weeks of supervised exercise in sedentary men on these variables. Subjects and methods We randomised 17 sedentary overweight male subjects (age $50 \pm 2.6$ years, BMI $27.6 \pm 0.5 \mathrm{~kg}$ /
\end{abstract}

Electronic supplementary material Supplementary material is available in the online version of this article at http://dx.doi.org/ $10.1007 / \mathrm{s} 00125-006-0498-7$ and is accessible to authorised users.

F. Shojaee-Moradie $(\bowtie) \cdot$ K. C. R. Baynes $\cdot$ C. Pentecost

N. C. Jackson $\cdot$ M. Stolinski $\cdot$ M. Whyte $\cdot$ S. B. Bowes $\cdot$

J. Gibney $\cdot$ R. H. Jones $\cdot$ A. M. Umpleby

Department of Diabetes, Endocrinology and Internal Medicine,

GKT School of Medicine, King's College London,

London, UK

e-mail: f.shojaee-moradie@surrey.ac.uk

F. Shojaee-Moradie

Wolfson Centre for Translational Research, Diabetes and

Endocrinology, Postgraduate Medical School,

University of Surrey,

Daphne Jackson Road, Manor Park,

Surrey GU2 7WG, UK

J. D. Bell • E. L. Thomas

MRI Unit, MRC Clinical Sciences Centre,

Hammersmith Hospital, Imperial College,

London, UK

D. Lovell

Department of Medical Statistics,

PGMS, University of Surrey,

Guildford, UK $\left.\mathrm{m}^{2}\right)$ to a 6 -week exercise programme $(n=10)$ or control group $(n=7)$. The insulin sensitivity of palmitic acid production rate $(\mathrm{Ra})$, glycerol $\mathrm{Ra}$, endogenous glucose $\mathrm{Ra}$ (EGP), glucose uptake and glucose metabolic clearance rate were measured at 0 and 6 weeks with a two-step hyperinsulinaemic-euglycaemic clamp [step 1, 0.3 (low dose); step 2, 1.5 (high dose) $\left.\mathrm{mU} \mathrm{kg}^{-1} \mathrm{~min}^{-1}\right]$. In the exercise group subjects were studied $>72 \mathrm{~h}$ after the last training session. Liver and skeletal muscle triacylglycerol content was measured by magnetic resonance spectroscopy and visceral adipose tissue by cross-sectional computer tomography scanning.

Results After 6 weeks, fasting glycerol, palmitic acid Ra $(p=0.003, p=0.042)$ and NEFA concentration $(p=0.005)$ were decreased in the exercise group with no change in the control group. The effects of low-dose insulin on EGP and of high-dose insulin on glucose uptake and metabolic clearance rate were enhanced in the exercise group but not in the control group ( $p=0.026 ; p=0.007$ and $p=0.04$ ). There was no change in muscle triacylglycerol and liver fat in either group.

Conclusions/interpretation Decreased availability of circulating NEFA may contribute to the observed improvement in the insulin sensitivity of EGP and glucose uptake following 6 weeks of moderate exercise.

Keywords Endogenous glucose production rate. Euglycaemic-hyperinsulinaemic clamp · Exercise . Glucose uptake · Insulin sensitivity · Lipolysis . Stable isotopes

\section{Abbreviations}

CT

EGP

${ }^{1} \mathrm{H}$-MRS $\quad{ }^{1} \mathrm{H}$-magnetic resonance spectroscopy 
IHCL

IMCL

MCR

Production rate

$V \mathrm{O}_{2 \max }$ intrahepatocellular lipid

intramyocellular lipid

metabolic clearance rate

$\mathrm{Ra}$

maximal aerobic capacity

\section{Introduction}

Although it is well known that established obesity is associated with insulin resistance, this association has also been reported in non-obese, but overweight individuals (BMI $25-30 \mathrm{~kg} / \mathrm{m}^{2}$ ) [1]. Specific factors which predispose these subjects to insulin resistance have been shown to be central fat distribution (both visceral and subcutaneous), also referred to as upper-body obesity, and low physical activity. Increased visceral fat may lead to the development of hepatic insulin resistance by increasing release of NEFA into the portal circulation [2], while increased subcutaneous fat may lead to release of more NEFA into the systemic circulation potentially leading to both peripheral and hepatic insulin resistance [3]. Fatty acid flux has been shown to be greater in obese individuals with upper-body obesity than in subjects with lower-body obesity $[4,5]$.

Elevated NEFA concentrations may cause insulin resistance by two mechanisms: substrate competition and inhibition of insulin signalling. Until recently it was considered that NEFA caused insulin resistance by the Randle cycle. This cycle proposed that increased NEFA oxidation restrained glucose oxidation in muscle by altering the redox potential of the cell and inhibiting key enzymes within the glycolytic cascade [6]. However, studies with ${ }^{1} \mathrm{H}$-magnetic resonance spectroscopy $\left({ }^{1} \mathrm{H}-\mathrm{MRS}\right)$ have shown that experimental elevation of NEFA concentration in plasma results in primary inhibition of glucose transport and phosphorylation in muscle $[7,8]$. There is evidence that this is due to inhibition of insulin signalling via phosphatidylinositol 3-kinase [8]. Increased NEFA concentrations have also been shown to enhance gluconeogenesis thus increasing endogenous glucose production (EGP) [3, 9], and there is evidence that this may also be due to inhibition of insulin signalling [10]. Finally, increased NEFA have been shown to increase insulin secretion of the beta cell in the pancreas [11].

Increased circulating NEFA may lead to an increased deposition of triacylglycerol in muscle and liver and this may also lead to insulin resistance in these tissues. Insulinstimulated glucose uptake is inversely correlated to intramyocellular lipid (IMCL) in normal subjects and offspring of type 2 diabetic patients [12] and subjects with increased liver fat have been shown to have reduced insulin sensitivity of EGP [13].

Exercise is a very effective way of improving insulin sensitivity. A 6-week exercise programme has been shown to increase insulin sensitivity by $40 \%$ in inactive subjects [14]. Although these authors did not separate the effect of exercise on insulin sensitivity into effects on EGP and peripheral glucose uptake the demonstration that exercise increased insulin-stimulated glycogen synthesis and insulinstimulated glucose transport-phosphorylation in muscle suggests increased insulin sensitivity of peripheral glucose disposal [13]. The mechanism for the improved insulin sensitivity of glucose metabolism following exercise is not clear. Some studies suggest that it may be related to a decrease in circulating NEFA [15] and a reduction in central obesity [16]. Since recent evidence suggests that insulin resistance may be due to the accumulation of lipid in liver and muscle, exercise-induced changes in this may also be a possible mechanism.

We investigated the effect of a 6-week supervised exercise programme on the insulin sensitivity of palmitic acid and glycerol metabolism (a measure of lipolysis), EGP and peripheral glucose uptake, intrahepatocellular lipid (IHCL) and IMCL and visceral obesity in sedentary male subjects. To study the chronic rather than the acute effects of exercise training, studies were undertaken $>72 \mathrm{~h}$ after the last exercise bout. Since EGP and lipolysis are sensitive to much lower concentrations of insulin than glucose uptake a two-step euglycaemic-hyperinsulinaemic clamp was used to measure insulin sensitivity. For the first step an insulin infusion rate of $0.3 \mathrm{mU} \mathrm{kg}^{-1} \mathrm{~min}^{-1}$ was used to measure the insulin sensitivity of EGP, glycerol and palmitic acid production rate $(\mathrm{Ra})$; for the second step a high dose insulin infusion rate of $1.5 \mathrm{mU}$ $\mathrm{kg}^{-1} \min ^{-1}$ was used to measure the insulin sensitivity of glucose uptake.

\section{Subjects and methods}

Subjects Sedentary healthy male adult subjects $(n=17)$ with BMI 25 to $30 \mathrm{~kg} / \mathrm{m}^{2}$ were recruited in response to an advertisement at King's College London. Subjects were excluded if they had diabetes mellitus, were taking lipidlowering medication or had clinically significant hyperlipidaemia (plasma triacylglycerol $>3.95 \mathrm{mmol} / 1$ or total cholesterol levels $>7.76 \mathrm{mmol} / \mathrm{l}$ ). Subjects with significant cardiorespiratory or locomotor problems precluding vigorous exercise and subjects already engaged in regular physical activity were also excluded. The study was approved by St Thomas' Hospital research ethics committee and all subjects gave informed consent.

The subjects were randomly allocated to an exercise group $(n=10)$ and a control group $(n=7)$. Subjects were interviewed by an exercise physiologist to establish that 
they were sedentary (defined as spending most of the day sitting and not participating in any recreational exercise).

Supervised training protocol Subjects allocated to the exercise group exercised at 60 to $85 \%$ of maximal aerobic capacity $\left(V \mathrm{O}_{2 \max }\right)$ for a minimum of $20 \mathrm{~min}$ at least three times per week for 6 weeks, as detailed in the Electronic supplementary material (ESM 1). The control group was asked to continue with their normal activity for the duration of the 6-week period. Both groups were asked not to change their dietary habits during the study.

$\mathrm{VO}_{2 \max } V \mathrm{O}_{2 \max }$ was measured using a step-wise maximal exercise test on an electronically braked bicycle ergonometer [17] as detailed in the ESM 1.

Study protocol Subjects were studied on two occasions, before ( 0 week) and after a 6 -week exercise programme or control period. Subjects were asked not to undertake any vigorous physical activity for $72 \mathrm{~h} \mathrm{[18]}$ and to fast overnight before the study day. On the day of the study, the subject was weighed and intravenous cannulae were inserted into the antecubital fossa of each arm: one for blood-taking and the other for the infusion of the isotopes, insulin and exogenous glucose. After taking initial (unenriched) blood samples, an infusion of $\left[1-{ }^{13} \mathrm{C}\right]$ palmitate bound to human albumin (5\%) (Grifols, Barcelona, Spain) $[19,20]\left(0.5 \mathrm{mg} \mathrm{kg}^{-1} \mathrm{~h}^{-1}\right)$, and primed infusions of $\left[1,1,2,3,3{ }^{2} \mathrm{H}_{5}\right]$ glycerol $\left(0.12 \mathrm{mg} / \mathrm{kg} ; 0.4 \mathrm{mg} \mathrm{kg}^{-1} \mathrm{~h}^{-1}\right)$ and $\left[6,6{ }^{2} \mathrm{H}_{2}\right]$ glucose $(170 \mathrm{mg} ; 1.7 \mathrm{mg} / \mathrm{min})$ were started. Once a steady state with the stable isotopes was achieved, a further five baseline samples were taken between 100 and $120 \mathrm{~min}$ to measure the enrichment of palmitic acid, glycerol and glucose, and concentrations of insulin, glucose, palmitic acid, NEFA and glycerol [20]. Samples were also taken for the measurement of adiponectin and glucagon concentration at baseline (100-120 min).

Three subjects from the exercise group and one from the control group did not receive $\left[1-{ }^{13} \mathrm{C}\right]$ palmitate due to problems with preparing this for the study.

At $120 \mathrm{~min}$ a two-step hyperinsulinaemic-euglycaemic clamp was started. Step 1 consisted of insulin infusion at $0.3 \mathrm{mU} \mathrm{kg}^{-1} \mathrm{~min}^{-1}$ (low dose) for $120 \mathrm{~min}$ to measure the insulin sensitivity of EGP, glycerol Ra and palmitic acid $\mathrm{Ra}$; step two consisted of insulin infusion at $1.5 \mathrm{mU} \mathrm{kg}^{-1}$ $\mathrm{min}^{-1}$ (high dose) for $180 \mathrm{~min}$ to measure the insulin sensitivity of glucose uptake [21]. Glucose concentration was maintained at euglycaemia using dextrose spiked with $\left[6,6-{ }^{2} \mathrm{H}_{2}\right]$ glucose $(8 \mathrm{mg} / \mathrm{g}$ glucose for step 1 and $10 \mathrm{mg} / \mathrm{g}$ glucose for step 2). Blood samples were taken every $30 \mathrm{~min}$ except between 210 and $240 \mathrm{~min}$ (low-dose steady state), and between 390 and 420 min (high-dose steady state) when samples were taken every $5 \mathrm{~min}$. Glucagon samples were taken at the end of each steady state.
Body composition and intracellular fat measurements Height, weight and WHR were measured before each metabolic study. IHCL and IMCL were measured by ${ }^{1} \mathrm{H}$-MRS within 1 week of the metabolic study and prior to the start of the exercise programme $[22,23]$ as detailed in ESM 1. Subjects were asked not to exercise for $72 \mathrm{~h}$ prior to the measurement. The measurements were repeated under the same conditions after the 6-week exercise or control period [24]. ${ }^{1} \mathrm{H}-\mathrm{MRS}$ could not be performed on one of the subjects in the control group due to metal implants and on one of the subjects in the exercise group due to technical problems with the scanner.

Computer tomography Computer tomography (CT) was used to measure cross-sectional abdominal visceral adipose tissue areas at L4/5 region and the cross-sectional muscle and adipose tissue areas of both legs at the mid-thigh region [25], as detailed in ESM 1. In three subjects subcutaneous abdominal fat could not be measured due to insufficient data collection.

Analytical methods Glucose, glycerol and palmitic acid isotopic enrichments and concentration of palmitic acid were measured by GC-MS on a HP 5971A MSD (Agilent Technologies, Wokingham, Berks, UK) according to methods previously described $[20,21,26]$ as detailed in ESM 1. Glycerol and glucose concentrations were also determined as detailed in ESM 1.

Insulin was measured using an in-house double antibody RIA [27] (intra-assay CV 6\%). Plasma adiponectin was measured by RIA using commercially available kits (Linco Research, St Louis, MO, USA; intra-assay CV 5\%). Serum NEFA concentration was determined using a commercially available kit (Wako Chemicals, Neuss, Germany; interassay CV 3.0\%).

Calculations EGP and glucose uptake were calculated using non-steady-state equations proposed by Steele and modified for stable isotopes [28]. The volume of distribution was assumed to be $22 \%$ of body weight. The calculation was also modified for inclusion of $\left[6,6{ }^{2} \mathrm{H}_{2}\right]$ glucose in the dextrose infusion [29]. Prior to calculation of glucose turnover, plasma glucose concentration and glucose enrichment time courses were smoothed using optimal segments technique analysis [30]. EGP was calculated at basal and following low-dose insulin. Glucose uptake and metabolic clearance rate (MCR) were calculated at basal and following high-dose insulin. Glucose MCR was calculated from glucose uptake/glucose concentration. Glycerol and palmitic acid $\mathrm{Ra}$ and uptake were also calculated using the non-steady-state Steele equations modified for stable isotopes at basal and following lowdose insulin. The volume of distribution for glycerol and 
palmitic acid were assumed to be 230 and $40 \mathrm{ml} / \mathrm{kg}$ respectively [19]. Insulin MCR at each steady state for the low-dose and high-dose insulin was calculated as the insulin infusion rate/insulin concentration.

Statistical analysis The results are presented as means \pm SE. Baseline characteristics of the two groups at 0 week and changes in measurements between baseline and 6 weeks in the two groups were compared using Student's $t$ tests. Repeated-measurements ANOVA followed by Bonferroni's multiple comparison test were used for statistical comparisons within the time courses of the experiments for insulin and glucose concentrations. Correlation for log adiponectin concentration with $\log$ IHCL content was made in SPSS (SPSS 12.0.2 for Windows; SPSS, Chicago, IL, USA) using Pearson's correlation. Within-group changes between baseline and 6 weeks were compared using paired $t$ tests. Intracellular fat measurements were analysed with a MannWhitney $U$ test. $p$ values $<0.05$ were considered statistically significant.

\section{Results}

Body composition and hormones Subjects in the exercise group did not differ from those in the control group with regard to age, BMI, WHR, fitness level (in terms of $V \mathrm{O}_{2 \max }$ ) and lipid profile at 0 week (Table 1). In the exercise group $V \mathrm{O}_{2 \max }$ increased by $20 \pm 5 \%$ after 6 weeks with no change in the control group ( $\Delta$ control vs $\Delta$ exercise, $p<0.001$ ) (Table 1 ). There was a $3 \pm 1 \%$ decrease in WHR in the exercise group, with no change in the control group ( $\Delta$ control vs $\Delta$ exercise, $p=0.03$ ) (Table 1). There was no significant change in body weight, BMI, or lipid profile in either group at 6 weeks. There was no significant difference in the change in adiponectin between 0 and 6 weeks in the two groups (Table 1).

At 0 week there was no difference in intra-abdominal and subcutaneous abdominal adipose tissue, leg subcutaneous adipose tissue and leg muscle as calculated from the CT scans (Table 2). After 6 weeks leg muscle was increased by $3.7 \pm 1 \%$ in the exercise group $(p=0.006)$, but the change between groups was not significant $(p=0.06)$. There was a significant within-group decrease in visceral fat in the exercise group $(p=0.034)$, but the change in visceral fat between groups was not significant. No significant change in leg fat or subcutaneous abdominal fat was seen in either group after 6 weeks.

IHCL and IMCL content of tibialis anterior muscle did not differ between groups at 0 week (Table 2). After 6 weeks, IHCL and IMCL contents did not change in either group (Table 2). Fasting log adiponectin concentration in all subjects at 0 week correlated inversely with $\log$ IHCL content $(r=-0.732, p=0.001)$.

Hyperinsulinaemic-euglycaemic clamp: EGP, glucose uptake and MCR Plasma glucose concentration at basal and during the hyperinsulinaemic-euglycaemic clamp with low-dose and high-dose insulin was not different within or between groups at 0 and 6 weeks (Fig. 1). Serum insulin concentration was not different within or between groups at 0 and 6 weeks at basal, during low-dose infusion and during high-dose infusion (Fig. 1).

No difference was seen in basal EGP between groups at 0 week (control group, $8.1 \pm 0.5 \mu \mathrm{mol} \mathrm{kg}^{-1} \mathrm{~min}^{-1}$; exercise

Table 1 Clinical characteristics

\begin{tabular}{|c|c|c|c|c|c|}
\hline & \multicolumn{2}{|c|}{ Control group } & \multicolumn{2}{|c|}{ Exercise group } & \multirow{2}{*}{$\begin{array}{l}p \text { value } \\
\Delta \text { control vs } \Delta \text { exe }\end{array}$} \\
\hline & 0 week & 6 weeks & 0 week & 6 weeks & \\
\hline Age (years) & $55 \pm 4$ & - & $47 \pm 3$ & - & \\
\hline Body weight (kg) & $84.1 \pm 2.5$ & $83.3 \pm 2.4$ & $87.4 \pm 2.8$ & $87.6 \pm 2.6$ & NS \\
\hline BMI $\left(\mathrm{kg} / \mathrm{m}^{2}\right)$ & $27.6 \pm 0.9$ & $27.4 \pm 0.9$ & $27.6 \pm 0.6$ & $27.5 \pm 0.6$ & NS \\
\hline Fat mass $(\mathrm{kg})$ & $20.5 \pm 1.9$ & $20.3 \pm 1.9$ & $22.4 \pm 1.6$ & $22.0 \pm 1.4$ & NS \\
\hline WHR & $1.00 \pm 0.02$ & $1.01 \pm 0.02$ & $0.98 \pm 0.02$ & $0.95 \pm 0.01 *$ & 0.03 \\
\hline$V \mathrm{O}_{2 \max }\left(\mathrm{ml} \mathrm{kg}^{-1} \min ^{-1}\right)$ & $27 \pm 2$ & $26 \pm 2$ & $31 \pm 1$ & $38 \pm 2 *$ & 0.001 \\
\hline HOMA-IR index & $2.54 \pm 0.6$ & $2.43 \pm 0.6$ & $2.44 \pm 0.5$ & $2.30 \pm 0.4$ & NS \\
\hline Total cholesterol $(\mathrm{mmol} / \mathrm{l})$ & $5.7 \pm 0.3$ & $5.8 \pm 0.4$ & $5.6 \pm 0.5$ & $5.5 \pm 0.4$ & NS \\
\hline Triacylglycerol (mmol/l) & $1.1 \pm 0.2$ & $1.2 \pm 0.2$ & $1.5 \pm 0.3$ & $1.5 \pm 0.3$ & NS \\
\hline LDL-cholesterol (mmol/l) & $4.1 \pm 0.3$ & $3.8 \pm 0.2$ & $3.8 \pm 0.4$ & $3.7 \pm 0.4$ & NS \\
\hline HDL-cholesterol $(\mathrm{mmol} / \mathrm{l})$ & $1.10 \pm 0.1$ & $1.04 \pm 0.1$ & $1.14 \pm 0.1$ & $1.24 \pm 0.1$ & NS \\
\hline Adiponectin $(\mu \mathrm{g} / \mathrm{ml})$ & $7.0 \pm 0.9$ & $6.6 \pm 1.0$ & $6.4 \pm 0.8$ & $5.4 \pm 0.7$ & NS \\
\hline
\end{tabular}

HOMA-IR, homeostatic model assessment of insulin resistance; exe, exercise group

$*_{p}<0.001$ vs 0 week

Basal measurements were not different between groups. 
Table 2 Body composition measured by CT scanning of intra-abdominal fat and subcutaneous abdominal fat and by ${ }^{1} \mathrm{H}-\mathrm{MRS}$ of intrahepatocellular lipid content and intramyocellular lipid content of tibialis anterior

\begin{tabular}{|c|c|c|c|c|c|}
\hline & \multicolumn{2}{|l|}{ Control group } & \multicolumn{2}{|l|}{ Exercise group } & \multirow{2}{*}{$\begin{array}{l}p \text { value } \\
\Delta \text { control vs } \Delta \text { exe }\end{array}$} \\
\hline & 0 week & 6 weeks & 0 week & 6 weeks & \\
\hline IA fat $\left(\mathrm{cm}^{2}\right)$ & $197.0 \pm 25.6$ & $181.4 \pm 26.7$ & $169.8 \pm 13.1$ & $139.2 \pm 10.0 *$ & NS \\
\hline $\mathrm{SC}$ fat $\left(\mathrm{cm}^{2}\right)$ & $395.8 \pm 52.3$ & $375.8 \pm 45.5$ & $334.6 \pm 37.6$ & $324.6 \pm 33.2$ & NS \\
\hline Leg fat $\left(\mathrm{cm}^{2}\right)$ & $64.7 \pm 9.4$ & $63.3 \pm 13.6$ & $81.1 \pm 11.8$ & $91.1 \pm 12.7$ & NS \\
\hline Leg muscle $\left(\mathrm{cm}^{2}\right)$ & $176.8 \pm 1.9$ & $166.8 \pm 1.2$ & $194.1 \pm 16.4$ & $204.0 \pm 17.2^{* *}$ & 0.061 \\
\hline IHCL, liver & $3.9(2.0-8.7)$ & $5.2(1.5-12.1)$ & $4.0(0.9-22.5)$ & $4.3(1.0-11.9)$ & NS \\
\hline IMCL, tibialis & $10.0(8.3-14.7)$ & $9.6(6.5-12.6)$ & $10.3(4.7-13.7)$ & $7.7(5.3-10.0)$ & NS \\
\hline
\end{tabular}

Results are mean \pm SEM or median (IQR). Values refer to the peak area of the IHCL signal with reference to the water peak after correcting for T1 and T2. Basal measurements were not different between groups.

$I A$ intra-abdominal, $S C$ subcutaneous, $I H C L$ intrahepatocellular lipid, $I M C L$ intramyocellular lipid, exe exercise group

${ }^{*} p=0.034$ vs 0 week

$* * p=0.006$ vs 0 week

group, $7.8 \pm 0.5 \mu \mathrm{mol} \mathrm{kg} \mathrm{kin}^{-1}$ ) or 6 weeks (control group, $7.5 \pm 0.7 \mu \mathrm{mol} \mathrm{kg} \mathrm{kin}^{-1}$; exercise group, $7.5 \pm$ $1.2 \mu \mathrm{mol} \mathrm{kg}{ }^{-1} \min ^{-1}$ ). Following low-dose insulin, EGP was lower in the exercise group at 6 weeks $(2.3 \pm 0.4 \mu \mathrm{mol}$ $\left.\mathrm{kg}^{-1} \min ^{-1}\right)$ than 0 week $\left(3.4 \pm 0.4 \mu \mathrm{mol} \mathrm{kg}{ }^{-1} \min ^{-1}\right)(p=$ $0.026)$. There was no change in the control group ( 0 week $3.1 \pm 0.7 \mu \mathrm{mol} \mathrm{kg} \mathrm{min}^{-1}$; 6 weeks; $3.2 \pm 0.4 \mu \mathrm{mol} \mathrm{kg}{ }^{-1}$ $\min ^{-1}$ ). The change in EGP with low-dose insulin was significantly different between groups ( $\Delta$ control vs $\Delta$ exercise, $p=0.014$ ) (Fig. 2a).

After 6 weeks, the glucose uptake following high-dose insulin infusion $\left(52.7 \pm 3.7 \mu \mathrm{mol} \mathrm{kg} \mathrm{min}^{-1}\right)$ was significantly greater in the exercise group than at 0 week $(45.1 \pm$ $\left.3.7 \mu \mathrm{mol} \mathrm{kg}{ }^{-1} \mathrm{~min}^{-1}\right)(p=0.007)$. This change in glucose uptake was greater than in the control group (45.3 \pm $3.0 \mu \mathrm{mol} \mathrm{kg}{ }^{-1} \mathrm{~min}^{-1}, 0$ week vs $46.2 \pm 3.3 \mu \mathrm{mol} \mathrm{kg} \mathrm{kg}^{-1}$ $\mathrm{min}^{-1}, 6$ weeks), but did not achieve statistical significance ( $\Delta$ control vs $\Delta$ exercise, $p=0.053$ ) (Fig. $2 b$ ).

After 6 weeks, the glucose infusion rate following highdose insulin infusion $\left(53.1 \pm 3.2 \mu \mathrm{mol} \mathrm{kg} \mathrm{kg}^{-1} \mathrm{~min}^{-1}\right)$ was significantly greater in the exercise group than at 0 week $\left(46.3 \pm 3.7 \mu \mathrm{mol} \mathrm{kg}{ }^{-1} \mathrm{~min}^{-1}\right)(p=0.016)$. This change in glucose infusion rate was greater than in the control group $\left(42.8 \pm 4.4 \mu \mathrm{mol} \mathrm{kg}{ }^{-1} \mathrm{~min}^{-1}\right.$, 0 week vs $44.2 \pm 3.8 \mu \mathrm{mol}$ $\mathrm{kg}^{-1} \min ^{-1}, 6$ weeks), but did not achieve statistical significance ( $\Delta$ control vs $\Delta$ exercise, $p=0.08$ ).

Basal glucose MCR was not different between groups at 0 week (control subjects, $1.8 \pm 0.1 \mathrm{ml} \mathrm{kg}^{-1} \mathrm{~min}^{-1}$; exercise group, $1.8 \pm 0.1 \mathrm{ml} \mathrm{kg}^{-1} \mathrm{~min}^{-1}$ ) or 6 weeks (control subjects, $1.6 \pm 0.1 \mathrm{ml} \mathrm{kg}^{-1} \mathrm{~min}^{-1}$; exercise group, $1.8 \pm 0.1 \mathrm{ml} \mathrm{kg}^{-1} \mathrm{~min}^{-1}$ ). After 6 weeks the change in glucose MCR following high-dose insulin infusion in the exercise group $\left(11.8 \pm 0.8 \mathrm{ml} \mathrm{kg}^{-1} \min ^{-1}\right.$ vs $10.2 \pm 0.8 \mathrm{ml}$ $\mathrm{kg}^{-1} \min ^{-1}, 0$ week) was significant $(p=0.04)$. This change in glucose MCR was greater than in the control
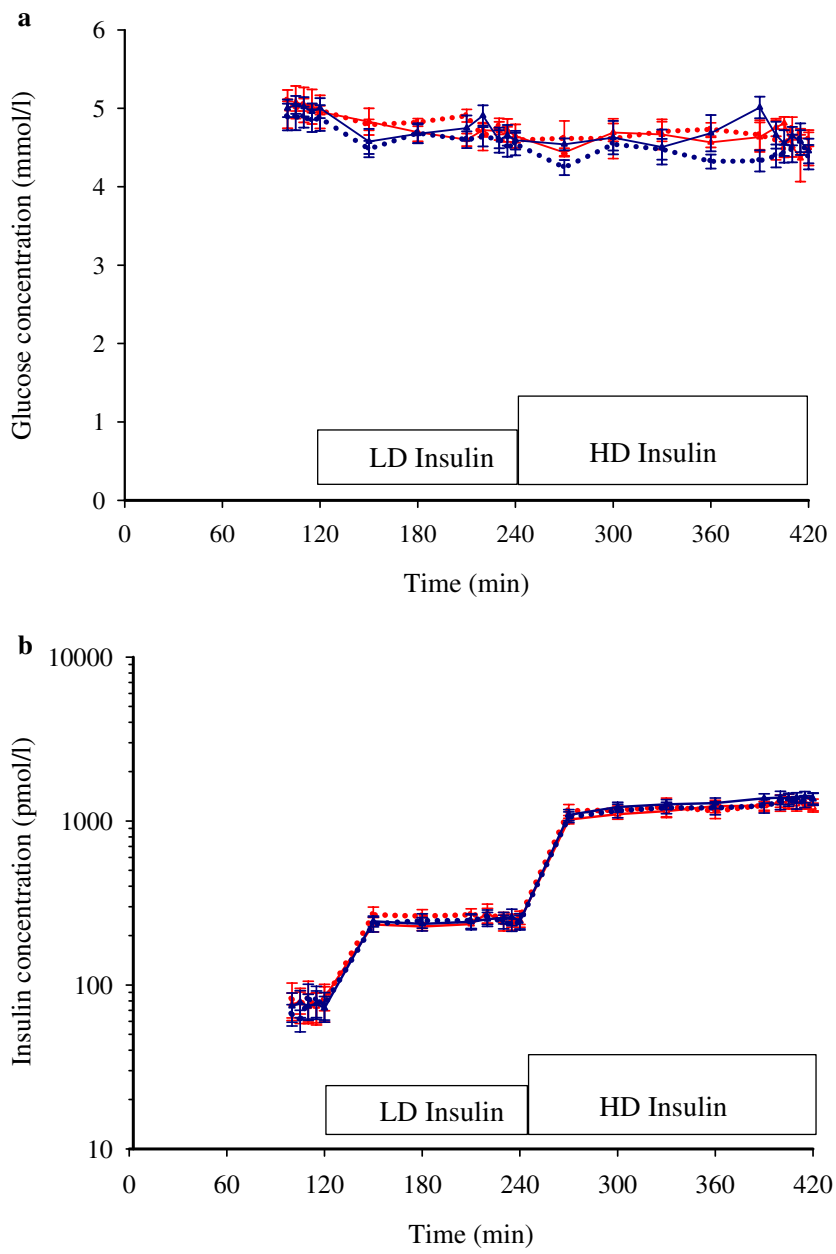

Fig. 1 Glucose (a) and insulin concentrations (b) in the exercise (blue line) and control groups (red line) at 0 week (dotted line $\bullet$ ) and 6 weeks (solid line $\boldsymbol{\Delta}$ ). There were no differences within or between groups in glucose or insulin concentrations, either at basal, or following the low-dose (LD) and high-dose (HD) insulin infusions. 

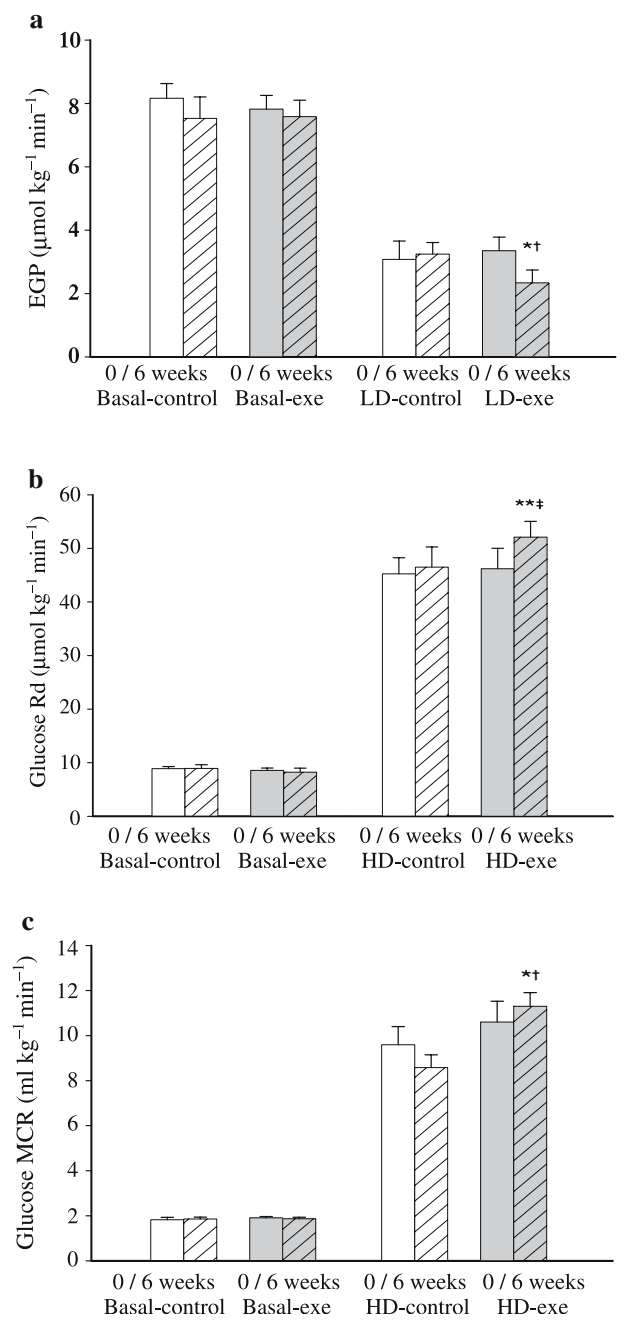

Fig. 2 Rates of a EGP, b glucose uptake $(R d)$, and $\mathbf{c}$ glucose MCR during basal and low-dose (LD) or high-dose (HD) insulin infusion in the control group (white bars) and exercise (exe) group (grey bars) at 0 week (open bars) and 6 weeks (hatched bars). ${ }^{*} p<0.03$ for 0 week vs 6 weeks; ${ }^{* *} p<0.01$ for 0 week vs 6 weeks; $\dagger p<0.04$ for $\Delta$ control vs $\Delta$ exe; $\ddagger p=0.053$ for glucose uptake). For actual $p$ values refer to the text

group (0 week, $9.4 \pm 0.9 \mathrm{ml} \mathrm{kg}^{-1} \mathrm{~min}^{-1}$; 6 weeks, $8.6 \pm$ $\left.0.5 \mathrm{ml} \mathrm{kg}^{-1} \mathrm{~min}^{-1}\right)(\Delta$ control vs $\Delta$ exercise, $p=0.048)$ (Fig. 2c).

NEFA, palmitic acid and glycerol concentration and $\mathrm{Ra}$ As shown in Table 3 and Fig. 3, basal NEFA, palmitic acid and glycerol concentration and basal palmitic acid and glycerol $\mathrm{Ra}$ and uptake at 0 week were not different between the two groups. After 6 weeks, basal NEFA and glycerol concentration decreased in the exercise group (both $p=0.005$ ), with no change in the control group. The change in basal NEFA and glycerol concentration in the exercise group was significantly different from the control group ( $\Delta$ control vs $\Delta$ exercise, $p=0.004$ and $p=0.021$, respectively). Basal palmitic acid concentration was lower after 6 weeks exercise, but this did not achieve statistical significance when compared with 0 week. When compared with the control group, the change in palmitic acid concentration was significantly different between groups ( $\Delta$ control vs $\Delta$ exercise, $p=0.018$ ).

Basal glycerol $\mathrm{Ra}\left(3.0 \pm 0.49 \mu \mathrm{mol} \mathrm{kg} \mathrm{kg}^{-1} \mathrm{~min}^{-1}\right)$ and palmitic acid $\mathrm{Ra}\left(1.5 \pm 0.1 \mu \mathrm{mol} \mathrm{kg} \mathrm{kg}^{-1}\right)$ were both lower after 6 weeks in the exercise group $(2.3 \pm 0.36 \mu \mathrm{mol}$ $\mathrm{kg}^{-1} \min ^{-1}, p=0.003$ and $1.23 \pm 0.16 \mu \mathrm{mol} \mathrm{kg} \min ^{-1}, p=$ 0.042 , respectively) with no change in these measurements in the control group (glycerol Ra, 0 week, $3.0 \pm 0.45 \mu \mathrm{mol}$ $\mathrm{kg}^{-1} \min ^{-1}$ vs 6 weeks, $3.0 \pm 0.44 \mu \mathrm{mol} \mathrm{kg}{ }^{-1} \mathrm{~min}^{-1}$; palmitic acid Ra, 0 week, $1.22 \pm 0.10 \mu \mathrm{mol} \mathrm{kg} \mathrm{kg}^{-1}$ vs 6 weeks $1.36 \pm 0.13 \mu \mathrm{mol} \mathrm{kg}{ }^{-1} \mathrm{~min}^{-1}$, respectively) (Fig. 3). Following low-dose insulin, palmitic acid Ra was lower at 6 weeks than 0 week in the exercise group, but this did not achieve statistical significance. The change in palmitic acid $\mathrm{Ra}$ with low-dose insulin was significantly different from the control group ( $\Delta$ control vs $\Delta$ exercise $p=0.028$ ). Glycerol Ra was not different following low-dose insulin after 6 weeks exercise.

Palmitic acid and glycerol uptake followed the same pattern as palmitic acid and glycerol $\mathrm{Ra}$ in both groups at basal and after the low-dose insulin infusion. Basal glycerol uptake $\left(3.0 \pm 0.54 \mu \mathrm{mol} \mathrm{kg}{ }^{-1} \mathrm{~min}^{-1}\right)$ and palmitic acid uptake $\left(1.55 \pm 0.08 \mu \mathrm{mol} \mathrm{kg}^{-1} \mathrm{~min}^{-1}\right)$ were both lower after 6 weeks in the exercise group $\left(2.3 \pm 0.39 \mu \mathrm{mol} \mathrm{kg}^{-1} \mathrm{~min}^{-1}\right.$, $p=0.012$ and $1.26 \pm 0.13 \mu \mathrm{mol} \mathrm{kg} \mathrm{kg}^{-1} \mathrm{~min}^{-1}, p=0.042$, respectively), with no change in these measurements in the control group (glycerol uptake; 0 week, $3.08 \pm 0.51 \mu \mathrm{mol}$ $\mathrm{kg}^{-1} \min ^{-1}$ vs 6 weeks, $3.07 \pm 0.48 \mu \mathrm{mol} \mathrm{kg} \mathrm{kin}^{-1}$; palmitic acid uptake, 0 week, $1.27 \pm 0.10 \mu \mathrm{mol} \mathrm{kg}^{-1} \mathrm{~min}^{-1}$ vs 6 weeks $1.39 \pm 0.12 \mu \mathrm{mol} \mathrm{kg}^{-1} \mathrm{~min}^{-1}$, respectively).

\section{Discussion}

Using a two-step euglycaemic-hyperinsulinaemic clamp, we demonstrated that 6 weeks of exercise training in sedentary male subjects resulted in increased insulin sensitivity of both EGP and peripheral glucose uptake. We also demonstrated that exercise training resulted in decreased fasting palmitic acid Ra, glycerol $\mathrm{Ra}$ and NEFA concentrations in the absence of any change in insulin concentrations, suggesting an increase in the insulin sensitivity of lipolysis.

The improvement of insulin sensitivity of EGP that is effected by chronic exercise training has not been previously demonstrated. Although DeFronzo et al. reported that a 6-week exercise training programme in moderately obese subjects improved the insulin sensitivity of EGP measured with a hyperinsulinaemic-euglycaemic clamp $\left(1 \mathrm{mU} \mathrm{kg}^{-1} \mathrm{~min}^{-1}\right)$ [31], the post-training assessments were made $48 \mathrm{~h}$ after the last exercise bout. It has 
Table 3 NEFA, glycerol and palmitic acid concentration at baseline and during the low-dose hyperinsulinaemic-euglycaemic clamp

\begin{tabular}{|c|c|c|c|c|c|}
\hline & \multicolumn{2}{|c|}{ Control group } & \multicolumn{2}{|c|}{ Exercise group } & \multirow{2}{*}{$\begin{array}{l}p \text { value } \\
\Delta \text { control vs } \Delta \text { exe }\end{array}$} \\
\hline & 0 week & 6 weeks & 0 week & 6 weeks & \\
\hline \multicolumn{6}{|l|}{ NEFA (mmol/l) } \\
\hline Basal & $0.70 \pm 0.08$ & $0.75 \pm 0.05$ & $0.74 \pm 0.05$ & $0.55 \pm 0.06^{* *}$ & 0.004 \\
\hline Low-dose insulin & $0.18 \pm 0.03$ & $0.21 \pm 0.03$ & $0.16 \pm 0.03$ & $0.12 \pm 0.02 *$ & 0.019 \\
\hline \multicolumn{6}{|l|}{ Glycerol ( $\mu \mathrm{mol} / \mathrm{l})$} \\
\hline Basal & $63 \pm 8.0$ & $59 \pm 4.7$ & $77 \pm 10.3$ & $55 \pm 5.9 *$ & 0.021 \\
\hline Low-dose insulin & $23 \pm 3.9$ & $22 \pm 3.4$ & $28 \pm 6.3$ & $21 \pm 4.4$ & NS \\
\hline \multicolumn{6}{|c|}{ Palmitic acid $(\mu \mathrm{mol} / \mathrm{l})$} \\
\hline Basal & $132 \pm 15$ & $144 \pm 19$ & $157 \pm 32$ & $133 \pm 35$ & 0.018 \\
\hline Low-dose insulin & $41 \pm 5$ & $46 \pm 6$ & $41 \pm 10$ & $34 \pm 8$ & NS \\
\hline
\end{tabular}

Basal measurements were not different between groups

exe exercise group

$* p=0.03$ vs 0 week

$* * p=0.005$ vs 0 week

been shown that the acute effect of exercise on insulin sensitivity is maintained for $48 \mathrm{~h}$, but is unmeasurable after $72 \mathrm{~h}$ [32]. In the current study all subjects were studied $72 \mathrm{~h}$ after the last exercise session. DiPietro et al. [33] found no difference in the insulin sensitivity of EGP after 9 months of exercise training at moderate or high intensity in older non-obese women studied $72 \mathrm{~h}$ after the final exercise bout and compared to a control group. This may be due to the lack of change in fitness, as $V \mathrm{O}_{2 \max }$ did not change with exercise training. In the current study there was a significant improvement in $V \mathrm{O}_{2 \max }$ following exercise training.

We also demonstrated that after exercise training glucose uptake and clearance increased with the high-dose insulin infusion in agreement with a previous study showing an improvement in peripheral insulin sensitivity following exercise training in insulin-resistant men, who were studied $96 \mathrm{~h}$ after the last exercise session [34].

We hypothesised that an improvement in insulin sensitivity after exercise training may be explained by adaptive changes in fatty acid metabolism, changes in visceral fat or changes in liver and muscle triacylglycerol content. We measured lipolysis in the fasting state and following lowdose insulin using isotopic tracers of both glycerol and palmitic acid. Whole-body glycerol Ra has been used in many studies to provide an estimate of the rate of lipolysis. However, this may overestimate lipolysis, since VLDL hydrolysis will contribute to glycerol Ra. Although this will be a small percentage of total glycerol $\mathrm{Ra}$ in the fasting state, during an hyperinsulinaemic clamp this contribution may increase, since insulin increases lipoprotein lipase mass and activity [35, 36]. Measurement of NEFA Ra using an isotope of one of the more abundant circulating fatty acids such as palmitic acid or oleic acid has also been used as a measure of whole-body lipolysis, although this may lead to an underestimation of lipolysis due to intracellular recycling of fatty acids into triacylglycerol. Both fasting glycerol $\mathrm{Ra}$ and palmitic acid Ra were reduced following an exercise programme in the current study, suggesting a decrease in fasting lipolysis. Since fasting insulin concentrations were not different after exercise training, an increase in the insulin sensitivity of lipolysis in the fasting state seems plausible. This supports the findings of a study that showed a decrease in lipolysis and hormone sensitive lipase activity in isolated adipocytes following endurance training for 4 months in obese subjects [37]. The suppression of NEFA concentration was significantly greater during the low-dose insulin infusion after 6 weeks exercise training, and although the suppression of glycerol and palmitic acid Ra was not different within groups, the decrease in palmitic acid Ra with low-dose insulin in the exercise group was significantly greater than in the control group. This also suggests an improvement in the insulin sensitivity of lipolysis.

The decrease in circulating NEFA may provide a mechanism for the improved insulin sensitivity of EGP and glucose uptake. Previous studies in obese subjects have shown that the insulin sensitivity of glucose production is reduced in the presence of elevated plasma NEFA concentrations resulting from an infusion of intralipid and heparin [38]. In type 2 diabetic subjects reduction of NEFA by administration of Acipimox $120 \mathrm{~min}$ before a euglycaemic-hyperinsulinaemic clamp study (108 pmol m${ }^{-2} \min ^{-1} ; 0.4 \mathrm{mU} \mathrm{kg}^{-1} \min ^{-1}$ ) was shown to reduce EGP [39], while in vitro increased NEFA levels have been shown to impair insulin binding and clearance in hepatocytes [40]. NEFA have also been shown to reduce insulin-stimulated glucose transport and whole-body glucose clearance in healthy subjects [41], while overnight administration of Acipimox has been 

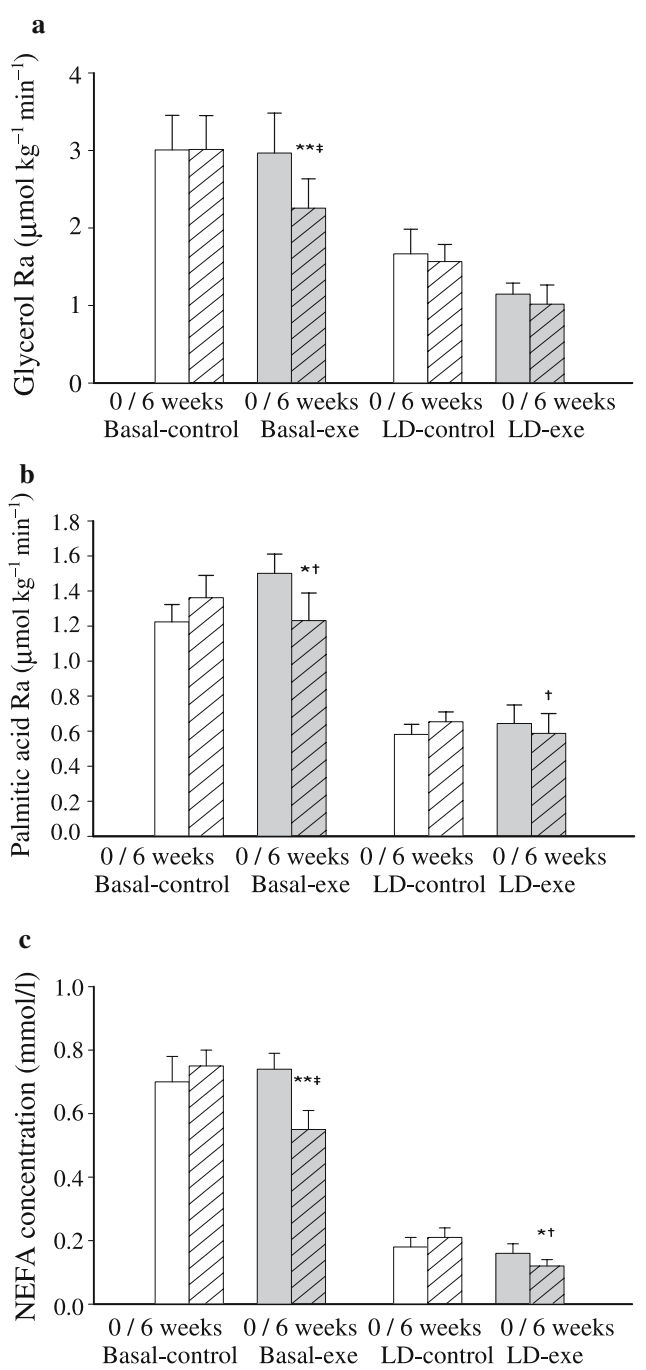

Fig. 3 Glycerol (a) and palmitic acid (b) Ra, and NEFA concentration (c) during basal and low-dose (LD) insulin infusion in the control (white bars) and exercise (exe) groups (grey bars) at 0 week (open bars) and 6 weeks (hatched bars). ${ }^{*} p<0.04$ for 0 week vs 6 weeks; $* * p<0.01$ for 0 week vs 6 weeks; $\nmid p<0.04$ for $\Delta$ control vs $\Delta$ exe; and $\ddagger p<0.01$ for $\Delta$ control vs $\Delta$ exe. For actual $p$ values refer to the text

shown to reduce NEFA and improve insulin sensitivity of glucose uptake in obese subjects [42]. Other factors may also contribute to the improvement of insulin sensitivity of peripheral glucose uptake, such as the increase in muscle mass.

The decrease in visceral fat in the exercise group may also have contributed to the improvement in insulin sensitivity of EGP. Venous drainage from visceral fat enters the hepatic portal circulation, thus NEFA released from visceral fat will reach the liver directly. Nielsen et al. measured the contribution of splanchnic lipolysis to hepatic NEFA delivery in lean and obese men and women, showing that this ranges from less than $10 \%$ to almost $50 \%$ and increases as a function of visceral fat [2]. As only a small percentage of NEFA from visceral fat reach the systemic circulation, a decrease in visceral fat would not be expected to affect systemic NEFA levels or palmitic acid Ra. The subcutaneous fat depot is thus largely responsible for the release of NEFA into the systemic circulation. We observed that there was no change in subcutaneous fat (measured by CT scanning of leg fat and abdominal subcutaneous fat), following the exercise programme, a finding that suggests that the decrease in lipolysis in the fasting state was not due to a decrease in subcutaneous fat mass.

Recent studies suggest that hepatic triacylglycerol content may be the main determinant of hepatic insulin resistance. Hepatic triacylglycerol content measured with proton spectroscopy is closely correlated with hepatic insulin sensitivity in type 2 diabetic patients [43] and in non-diabetic men [13]. In the latter study, this was independent of intra-abdominal obesity measured by MRI and of overall obesity, whereas a subsequent study in patients with type 2 diabetes found liver triacylglycerol to be closely related to visceral fat measured by CT [44]. In the current study, the increase in the insulin sensitivity of EGP occurred in the absence of any significant change in IHCL. However, there was a large variance in IHCL and the study may have been not sufficiently powered to detect any significant change.

Intracellular muscle triacylglycerol deposition has also been shown to retard GLUT4 trafficking, thereby reducing glucose entry into cells [8]. Reduction in muscle triacylglycerol by dietary restriction has been shown to improve muscle glucose uptake, but in the present study the exercise programme did not affect IMCL, suggesting the relationship between IMCL and insulin sensitivity may also reflect other factors [45].

In summary, this study suggests that an improvement in the insulin sensitivity of lipolysis, resulting in decreased availability of circulating NEFA, may contribute to the observed improvement in hepatic insulin sensitivity of EGP and peripheral insulin sensitivity of glucose uptake following an exercise programme. While it is well recognised that insulin sensitivity is improved following exercise training in patients with type 2 diabetes and obesity, this is the first study to show that the chronic effects of exercise training ( $>72 \mathrm{~h}$ after the last bout of exercise) results in improved insulin sensitivity of wholebody lipolysis in the fasting state and of endogenous glucose production rate during a euglycaemic-hyperinsulinaemic clamp.

Acknowledgements This study was funded by the British Heart Foundation (PG/2000056). We are grateful for the technical assistance of P. Croos and W. Jefferson. We would also like to thank N. Patel and G. Hamilton for their help with this project.

Duality of interest The authors state that there is no duality of interest. 


\section{References}

1. Ruderman N, Chisholm D, Pi-Sunyer X, Schneider S (1998) The metabolically obese, normal-weight individual revisited. Diabetes 47:699-713

2. Nielsen S, Guo Z, Johnson CM, Hensrud DD, Jensen MD (2004) Splanchnic lipolysis in human obesity. J Clin Invest 113:1582-1588

3. Horowitz JF, Coppack SW, Klein S (2001) Whole-body and adipose tissue glucose metabolism in response to short-term fasting in lean and obese women. Am J Clin Nutr 73:517-522

4. Jensen MD, Haymond MW, Rizza RA, Cryer PE, Miles JM (1989) Influence of body fat distribution on free fatty acid metabolism in obesity. J Clin Invest 83:1168-1173

5. Boden G (1998) Free fatty acids (FFA), a link between obesity and insulin resistance. Front Biosci 3:D169-D175

6. Randle PJ, Garland PB, Hales CN, Newsholme EA (1963) The glucose fatty-acid cycle. Its role in insulin sensitivity and the metabolic disturbances of diabetes mellitus. Lancet 1:785-789

7. Roden M, Krssak M, Stingl H et al (1999) Rapid impairment of skeletal muscle glucose transport/phosphorylation by free fatty acids in humans. Diabetes 48:358-364

8. Dresner A, Laurent D, Marcucci M et al (1999) Effects of free fatty acids on glucose transport and IRS-1-associated phosphatidylinositol 3-kinase activity. J Clin Invest 103:253-259

9. Wiesenthal SR, Sandhu H, McCall RH et al (1999) Free fatty acids impair hepatic insulin extraction in vivo. Diabetes 48:766-774

10. Griffin ME, Marcucci MJ, Cline GW et al (1999) Free fatty acidinduced insulin resistance is associated with activation of protein kinase $\mathrm{C}$ theta and alterations in the insulin signalling cascade. Diabetes 48:1270-1274

11. Stein DT, Esser V, Stevenson BE et al (1996) Essentiality of circulating fatty acids for glucose-stimulated insulin secretion in the fasted rat. J Clin Invest 97:2728-2735

12. Virkamaki A, Korsheninnikova E, Seppala-Lindroos A et al (2001) Intramyocellular lipid is associated with resistance to in vivo insulin actions on glucose uptake, antilipolysis, and early insulin signaling pathways in human skeletal muscle. Diabetes 50:2337-2343

13. Seppala-Lindroos A, Vehkavaara S, Hakkinen AM et al (2002) Fat accumulation in the liver is associated with defects in insulin suppression of glucose production and serum free fatty acids independent of obesity in normal men. J Clin Endocrinol Metab 87:3023-3028

14. Perseghin G, Price TB, Petersen KF et al (1996) Increased glucose transport-phosphorylation and muscle glycogen synthesis after exercise training in insulin-resistant subjects. $\mathrm{N}$ Engl J Med 335:1357-1362

15. Boden G (1997) Role of fatty acids in the pathogenesis of insulin resistance and NIDDM. Diabetes 46:3-10

16. Meek SE, Nair KS, Jensen MD (1999) Insulin regulation of regional free fatty acid metabolism. Diabetes 48:10-14

17. Borg G, Linderholm H (1967) Perceived exertion and pulse rate during graded exercise in various age groups. Acta Med Scand (Suppl) 472:194-206

18. Eriksson J, Taimela S, Koivisto VA (1997) Exercise and the metabolic syndrome. Diabetologia 40:125-135

19. Romijn JA, Coyle EF, Sidossis LS et al (1993) Regulation of endogenous fat and carbohydrate metabolism in relation to exercise intensity and duration. Am J Physiol 265:E380E391

20. Gibney J, Healy ML, Stolinski M et al (2003) Effect of growth hormone $(\mathrm{GH})$ on glycerol and free fatty acid metabolism during exhaustive exercise in GH-deficient adults. J Clin Endocrinol Metab 88:1792-1797
21. Brackenridge A, Pearson ER, Shojaee-Moradie F, Hattersley AT, Russell-Jones D, Umpleby AM (2006) Contrasting insulin sensitivity of endogenous glucose production rate in subjects with hepatocyte nuclear factor-1beta and-1alpha mutations. Diabetes $55: 405-411$

22. Rico-Sanz J, Hajnal JV, Thomas EL, Mierisova S, Ala-Korpela M, Bell JD (1998) Intracellular and extracellular skeletal muscle triglyceride metabolism during alternating intensity exercise in humans. J Physiol 510:615-622

23. Rico-Sanz J, Thomas EL, Jenkinson G, Mierisova S, Iles R, Bell JD (1999) Diversity in levels of intracellular total creatine and triglycerides in human skeletal muscles observed by (1)H-MRS. J Appl Physiol 87:2068-2072

24. Szczepaniak LS, Nurenberg P, Leonard D et al (2005) Magnetic resonance spectroscopy to measure hepatic triglyceride content: prevalence of hepatic steatosis in the general population. Am J Physiol Endocrinol Metab 288:E462-E468

25. Rendell M, Hulthen UL, Tornquist C, Groop L, Mattiasson I (2001) Relationship between abdominal fat compartments and glucose and lipid metabolism in early postmenopausal women. J Clin Endocrinol Metab 86:744-749

26. Shojaee-Moradie F, Jackson NC, Jones RH, Mallet AI, Hovorka R, Umpleby AM (1996) Quantitative measurement of 3-O-methyl-dglucose by gas chromatography-mass spectrometry as a measure of glucose transport in vivo. J Mass Spectrom 31:961-966

27. Sonksen PH (1976) Double antibody technique for the simultaneous assay of insulin and growth hormone. In: Antoniades HN (ed) Hormones in human blood: detection and assay. Harvard University Press, Cambridge, MA, pp 176-199

28. Steele R, Bishop JS, Dunn A, Altszuler N, Rathbeb I, Debodo RC (1965) Inhjbition by insulin of hepatic glucose production in the normal dog. Am J Physiol 208:301-306

29. Finegood DT, Bergman RN, Vranic M (1987) Estimation of endogenous glucose production during hyperinsulinemic-euglycemic glucose clamps. Comparison of unlabeled and labeled exogenous glucose infusates. Diabetes 36:914-924

30. Finegood DT, Bergman RN (1983) Optimal segments: a method for smoothing tracer data to calculate metabolic fluxes. Am J Physiol 244:E472-E479

31. DeFronzo RA, Sherwin RS, Kraemer N (1987) Effect of physical training on insulin action in obesity. Diabetes 36:1379-1385

32. Eriksson J, Taimela S, Koivisto VA (1997) Exercise and the metabolic syndrome. Diabetologia 40:125-135

33. DiPietro L, Dziura J, Yeckel CW, Neufer PD (2006) Exercise and improved insulin sensitivity in older women: evidence of the enduring benefits of higher intensity training. J Appl Physiol 100:142-149

34. Hughes VA, Fiatarone MA, Fielding RA et al (1993) Exercise increases muscle GLUT-4 levels and insulin action in subjects with impaired glucose tolerance. Am J Physiol 264:E855-E862

35. Eckel RH, Yost TJ, Jensen DR (1995) Alterations in lipoprotein lipase in insulin resistance. Int J Obes Relat Metab Disord 19 (Suppl 1):S16-S21

36. Miyashita Y, Ebisuno M, Ohhira M et al (2006) Enhancement of serum lipoprotein lipase mass levels by intensive insulin therapy. Diabetes Res Clin Pract 72:61-67

37. De Glisezinski I, Crampes F, Harant I et al (1998) Endurance training changes in lipolytic responsiveness of obese adipose tissue. Am J Physiol 275:E951-E956

38. Bevilacqua S, Bonadonna R, Buzzigoli G et al (1987) Acute elevation of free fatty acid levels leads to hepatic insulin resistance in obese subjects. Metabolism 36:502-506

39. Saloranta C, Franssila-Kallunki A, Ekstrand A, Taskinen MR, Groop L (1991) Modulation of hepatic glucose production by non-esterified fatty acids in type 2 (non-insulin-dependent) diabetes mellitus. Diabetologia 34:409-415 
40. Svedberg J, Bjorntorp P, Smith U, Lonnroth P (1990) Free-fatty acid inhibition of insulin binding, degradation, and action in isolated rat hepatocytes. Diabetes 39:570-574

41. Krebs M, Krssak M, Nowotny P et al (2001) Free fatty acids inhibit the glucose-stimulated increase of intramuscular glucose-6phosphate concentration in humans. J Clin Endocrinol Metab $86: 2153-2160$

42. Santomauro AT, Boden G, Silva ME et al (1999) Overnight lowering of free fatty acids with Acipimox improves insulin resistance and glucose tolerance in obese diabetic and nondiabetic subjects. Diabetes 48:1836-1841
43. Ryysy L, Hakkinen AM, Goto T et al (2000) Hepatic fat content and insulin action on free fatty acids and glucose metabolism rather than insulin absorption are associated with insulin requirements during insulin therapy in type 2 diabetic patients. Diabetes 49:749-758

44. Kelley DE, McKolanis TM, Hegazi RA, Kuller LH, Kalhan SC (2003) Fatty liver in type 2 diabetes mellitus: relation to regional adiposity, fatty acids, and insulin resistance. Am J Physiol Endocrinol Metab 285:E906-E916

45. Frost GS, Goff LM, Hamilton G et al (2003) Carbohydrateinduced manipulation of insulin sensitivity independently of intramyocellular lipids. Br J Nutr 89:365-375 